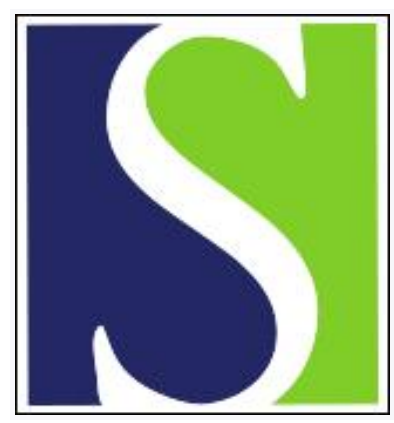

Scand J Work Environ Health 2001;27(1):30-40

https://doi.org/10.5271/sjweh.584

Issue date: Feb 2001

Questionnaire versus direct technical measurements in assessing postures and movements of the head, upper back, arms and hands

by Hansson G- $\AA$, Balogh I, Unge Byström J, Ohlsson K, Nordander C, Asterland P, Sjölander S, Rylander L, Winkel J, Skerfving S; Malmö Shoulder-Neck Study Group

Affiliation: Department of Occupational and Environmental Medicine, University Hospital, SE-221 85 Lund, Sweden. gert-ake.hansson@ymed.lu.se

Refers to the following texts of the Journal: 1999;25(2):81-83

1996;22(4):251-259 1997;23(5):370-377 1998;24(5):376-385

$1999 ; 25(2): 105-114 \quad 1999 ; 25(3): 246-254 \quad 1999 ; 25(1): 57-66$

1996;22(3):176-181

The following articles refer to this text: 2009;35(2):85-95;

2009;35(4):245-260; 2017;43(3):269-278; 2022;48(2):137-147;

2022;48(8):651-661

Key terms: arm; assessment; goniometer; hand; head; inclinometer; job; mechanical exposure; misclassification; movement; MSD; musculoskeletal disorder; occupation; posture; questionnaire; technical measurements; upper back; workload

This article in PubMed: www.ncbi.nlm.nih.gov/pubmed/11266144

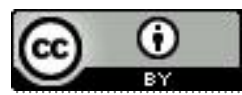




\title{
Questionnaire versus direct technical measurements in assessing postures and movements of the head, upper back, arms and hands
}

\author{
by Gert-Åke Hansson, DrMedSc, 1,2,3,5 Istvan Balogh, LicEng, 1,2,3,5 Jeannette Unge Byström, MSc, 1,2,3 \\ Kerstina Ohlsson, DrMedSc, 1,2,3,5 Catarina Nordander, MD, ${ }^{1,2,3}$ Paul Asterland, MSc, ${ }^{1,2,3}$ Simon Sjölander, \\ MSc, ${ }^{1,2,3,5}$ Lars Rilander, DrMedSc, ${ }^{1,2,3}$ Jergen Winkel, DrMedSc, ${ }^{2,3,45}$ Staffan Skerfving, MD, ${ }^{1,2,3}$ Malmö \\ Shoulder-Neck Study Group
}

\begin{abstract}
Hansson GÅ, Balogh I, Unge Byström J, Ohlsson K, Nordander C, Asterland P, Sjölander S, Rylander L, Winkel J, Skerfving S, Malmö Shoulder-Neck Study Group. Questionnaire versus direct technical measurements in assessing postures and movements of the head, upper back, arms and hands. Scand J Work Environ Health 2001;27(1):30-40.
\end{abstract}

\begin{abstract}
Objectives This study compares questionnaire-assessed exposure data on work postures and movements with direct technical measurements.

Methods Inclinometers and goniometers were used to make full workday measurements of 41 office workers and 41 cleaners, stratified for such factors as musculoskeletal complaints. The subjects answered a questionnaire on work postures of the head, back, and upper arms and repeated movements of the arms and hands (3-point scales). The questionnaire had been developed on the basis of a previously validated one. For assessing worktasks and their durations, the subjects kept a 2-week worktask diary. Job exposure was individually calculated by time-weighting the task exposure measurements according to the diary.

Results The agreement between the self-assessed and measured postures and movements was low (kappa = 0.06 for the mean within the occupational groups and kappa $=0.27$ for the whole group). Cleaners had a higher measured workload than office workers giving the same questionnaire response. Moreover, the subjects with neck-shoulder complaints rated their exposure to movements as higher than those without complaints but with the same measured mechanical exposure. In addition, these subjects also showed a general tendency to rate their postural exposure as higher. The women rated their exposure higher than the men did.

Conclusions The questionnaire-assessed exposure data had low validity. For the various response categories the measured exposure depended on occupation. Furthermore, there was a differential misclassification due to musculoskeletal complaints and gender. Thus it seems difficult to construct valid questionnaires on mechanical exposure for establishing generic exposure-response relations in epidemiologic studies, especially cross-sectional ones. Direct technical measurements may be preferable.
\end{abstract}

Key terms goniometer, inclinometer, job, mechanical exposure, misclassification, musculoskeletal disorders, occupation, workload.

Preventive actions against work-related musculoskeletal disorders have not, so far, been very effective (1). Their relation to work has 2 aspects, the mechanical (physical) and the psychosocial (2). The relative significance of these 2 types of exposures, and their possible interaction, are poorly known. Therefore, the Malmö Shoulder-Neck Study was initiated to focus on these issues (3). Due to the cohort size - the study involves about 15000 inhabitants in the city of Malmö, Sweden - questionnaires were used instead of observations or direct measurements.

However, it is not known how to construct an optimal questionnaire and what information can be obtained (4). Many types of questionnaires have been evaluated

\author{
Department of Occupational and Environmental Medicine, University Hospital, Lund, Sweden. \\ Change@Work, Lund University, Lund, Sweden. \\ Malmö Shoulder-Neck Study Group, Department of Community Medicine, Lund University, Malmö, Sweden. \\ National Institute for Working Life, Solna, Sweden. \\ Division of Production Ergonomics, Faculty of Technology and Society, Malmö University, Malmö, Sweden.
}

Reprint requests to: Dr Gert-Åke Hansson, Department of Occupational and Environmental Medicine, University Hospital, SE—221 85 Lund, Sweden. [E-mail: gert-ake.hansson@ymed.lu.se] 
(5-13). The results vary however, some showing high validity and reliability and others indicating nondifferential or differential misclassification that may affect the risk estimates through dilution or systematic error. A particular problem is any differential misclassification of exposure due to work-related musculoskeletal disorders $(14,15)$.

On the basis of an evaluation of a previous questionnaire (5), which showed that agreement was poor at a detailed level, the questionnaire employed in our study used a 3-point scale for assessing postures and movements. The rating was made according to the perceived exposure quantity.

A straightforward way to evaluate the misclassification of self-assessed exposure is to compare the assessment with the results of direct technical measurements $(16,17)$. Recent developments in electronics and personal computers have made whole-day field measurements feasible (18-20).

The aim of our study was to evaluate the agreement between questionnaire-assessed and technically measured mechanical exposure to different postures and movements. Possible differential misclassification according to occupation, musculoskeletal complaints, gender, and age was of special interest.

\section{Subjects and methods}

\section{Questionnaire}

The Malmö Shoulder-Neck Study used a postal questionnaire comprising 144 questions (3). Seven of these questions, all of which aimed at specific work postures or movements and used a 3-point scale ("very little or not at all", "somewhat", and "much") were evaluated (table 1).

The questionnaire also included questions on subjective complaints from the neck, shoulders and elbowshands during the last 12 months (21). The responses were modified to a 5-point scale ("never", "occasionally", "sometimes", "often", and "all the time").

\section{Study groups}

Office workers and cleaners were studied. These groups were the 2 largest ones in the Malmö Shoulder-Neck Study population, and, moreover, they showed large contrast with respect to self-assessed postures and movements. However, the study base was not part of the Malmö Shoulder-Neck Study.

All 363 male and female office workers in 2 municipal offices and 1 company office and all 273 female cleaners at 4 hospitals in southern Sweden received the questionnaire.

Of the 276 office workers who answered the questionnaire, 41 subjects $\geq 45$ years of age were selected for measurement (table 2). Stratification was made according to gender and reported complaints from the neck or shoulders (responses "often" or "all the time" and responses "never" or "occasionally", including elbows and hands). The chosen definition of complaints excluded the intermediate group, and thus enhanced the contrast. The main worktasks were varied office work, work with video display units, meeting attendance and walking between localities.

Of the 218 cleaners who answered the questionnaire, a stratified selection of 41 subjects was made for the measurements (table 2). The stratification was based on age ( $<45$ or $\geq 45$ years) and reported complaints from the neck or shoulders (yes or no). The cleaners

Table 1. Items used in the questionnaire to assess postures and movements and the corresponding methods and measures used for validation.

\begin{tabular}{|c|c|c|c|c|}
\hline Questionnaire item & $\begin{array}{l}\text { Measurement } \\
\text { method }\end{array}$ & Region & Measure & $\begin{array}{l}\text { Distribution } \\
\text { (percentile) }\end{array}$ \\
\hline \multicolumn{5}{|l|}{ Postures } \\
\hline $\begin{array}{l}\text { Does your work involve that you work with your head } \\
\text { Bent backward? } \\
\text { Bent forward a little? } \\
\text { Bent forward a lot? }\end{array}$ & $\begin{array}{l}\text { Inclinometer } \\
\text { Inclinometer } \\
\text { Inclinometer }\end{array}$ & $\begin{array}{l}\text { Head } \\
\text { Head } \\
\text { Head }\end{array}$ & $\begin{array}{l}\text { Angle (degrees) } \\
\text { Angle (degrees) } \\
\text { Angle (degrees) }\end{array}$ & $\begin{array}{l}\text { 1st, 10th } \\
\text { 90th, 99th } \\
\text { 90th, 99th }\end{array}$ \\
\hline $\begin{array}{l}\text { Does your work involve that you work with your back } \\
\text { Bent forward a lot? } \\
\text { Does your work involve that you work with your arms }\end{array}$ & Inclinometer & Upper back & Angle (degrees) & 90th, 99th \\
\hline Bevated or stretched forward? & Inclinometer & Upper arms & Angle (degrees) & 90th, 99th \\
\hline Movements & & & & \\
\hline $\begin{array}{l}\text { Does your work involve that you perform the same } \\
\text { Arm movements many times per minute? } \\
\text { Wrist movements many times per minute? }\end{array}$ & $\begin{array}{l}\text { Inclinometer } \\
\text { Goniomete }\end{array}$ & $\begin{array}{l}\text { Upper arms } \\
\text { Wrists }^{\mathrm{a}}\end{array}$ & $\begin{array}{l}\text { Angular velocity (degrees/s) } \\
\text { Angular velocity (degrees/s) } \\
\left.\text { Angular acceleration (degrees } / \mathrm{s}^{2}\right) \\
\text { Velocity }<1 \text { degrees } / \mathrm{s}(\% \text { time) } \\
\text { Repetitiveness }(\mathrm{Hz})\end{array}$ & $\begin{array}{l}\text { 90th, 99th } \\
\text { 90th, 99th } \\
\text { 90th, 99th }\end{array}$ \\
\hline
\end{tabular}

${ }^{a}$ Fexion measures used. 
Table 2. Employment time for the 82 subjects, stratified according to occupation, neck-shoulder complaints, gender, and age.

\begin{tabular}{|c|c|c|c|c|c|c|c|c|c|c|}
\hline \multirow[t]{4}{*}{ Group } & \multicolumn{8}{|c|}{ Complaint } & & \\
\hline & \multicolumn{5}{|c|}{ No } & \multicolumn{5}{|c|}{ Yes } \\
\hline & \multirow[t]{2}{*}{$\mathrm{N}$} & \multicolumn{2}{|c|}{$\begin{array}{l}\text { Age } \\
\text { (years) }\end{array}$} & \multicolumn{2}{|c|}{$\begin{array}{l}\text { Employment time } \\
\text { (years) }\end{array}$} & \multirow[t]{2}{*}{$\mathrm{N}$} & \multicolumn{2}{|c|}{$\begin{array}{l}\text { Age } \\
\text { (years) }\end{array}$} & \multicolumn{2}{|c|}{$\begin{array}{l}\text { Employment time } \\
\text { (years) }\end{array}$} \\
\hline & & Mea & Range & Mean & Range & & Mean & Range & Mean & Range \\
\hline \multicolumn{11}{|c|}{ Office workers ( $>45$ years) } \\
\hline $\begin{array}{l}\text { Women } \\
\text { Men }\end{array}$ & $\begin{array}{l}12 \\
12\end{array}$ & $\begin{array}{l}52 \\
50\end{array}$ & $\begin{array}{l}45-63 \\
45-55\end{array}$ & $\begin{array}{l}21 \\
18\end{array}$ & $\begin{array}{l}9-35 \\
1-41\end{array}$ & $\begin{array}{r}12 \\
5\end{array}$ & $\begin{array}{l}55 \\
50\end{array}$ & $\begin{array}{l}47-61 \\
46-54\end{array}$ & $\begin{array}{l}22 \\
20\end{array}$ & $\begin{array}{l}5-36 \\
8-32\end{array}$ \\
\hline \multicolumn{11}{|c|}{ Ceaners (females ) } \\
\hline $\begin{array}{l}<45 \text { years } \\
\geq 45 \text { years }\end{array}$ & $\begin{array}{l}9 \\
8\end{array}$ & $\begin{array}{l}31 \\
53\end{array}$ & $\begin{array}{l}24-36 \\
46-60\end{array}$ & $\begin{array}{l}13 \\
19\end{array}$ & $\begin{array}{l}6-18 \\
7-27\end{array}$ & $\begin{array}{l}11 \\
13\end{array}$ & $\begin{array}{l}38 \\
50\end{array}$ & $\begin{array}{l}32-44 \\
45-62\end{array}$ & $\begin{array}{l}15 \\
15\end{array}$ & $\begin{array}{l}7-27 \\
6-25\end{array}$ \\
\hline
\end{tabular}

performed various cleaning tasks, maintained their equipment, attended meetings, and moved between localities.

\section{Measurements}

Inclinometers were used for recording the angle, relative to the line of gravity, for the head, the upper back, and both upper arms $(18,22,23)$. One inclinometer was placed on the forehead and another to the right of the cervicothoracic spine at the C7-Th1 level. For the upper arms, the inclinometers were fixed to plastic plates $(55 \times 27 \mathrm{~mm})$ that were placed along the upper arm, with the lateral edge along the line from the lateral-posterior corner of the acromion to the lateral epicondyle, and the upper edge at the insertion of the deltoid muscle. For the head and upper back, the forward-backward projection of the inclination angle (flexion below) and their time derivatives were used to characterize postures and movements. Upper-arm elevation and the time derivative of the position on the unit sphere (as described by spherical co-ordinates), were used for the postures and movements, respectively. Various percentiles of the angle and angular velocity distributions were calculated (table 1). The reference position for the head and upper back (flexion 0 degrees) was defined as the position obtained when the subject was standing upright and looking at a mark at eye level. The forward direction of the head and back was defined with the subject sitting, leaning straight forward, and looking at the floor. For the upper arms, the reference position (elevation 0 degrees) was recorded with the subject sitting, with the side of the body leaning towards the rest of the chair, with the arm hanging perpendicular over the rest of the chair, and with a 2-kg dumbbell in the hand.

Wrist positions and movements, for both flexionextension (flexion) and ulnar-radial deviation, were recorded for both the right and left sides. Biaxial flexible goniometers (M110, Biometrics Ltd, Blackwood, Gwent, United Kingdom) were placed over the wrists $(20,22-26)$. In a previous study we showed that the main error of the goniometer is crosstalk and that a sampling frequency of $20 \mathrm{~Hz}$ and a low-pass filter of 5 $\mathrm{Hz}$ are suitable for recording and characterizing wrist positions and movements (20). In addition to the previously used measures, the angular acceleration was calculated from the angular velocity data, using the 3-point 1 st-order central difference. The reference position $(0$ degrees of flexion and deviation) was recorded with the subject standing and with the arms and hands hanging relaxed alongside the body. Since relative errors due to crosstalk are smaller in flexion measures, as compared with deviation ones (20), the former were chosen to characterize the wrist movements (table 1).

Postures and movements were continuously recorded for each subject during a full workday of $4-8$ hours. Data loggers, with a sampling rate of $20 \mathrm{~Hz}$, were used for data acquisition (19). After the recording, the data were transferred to a personal computer and analyzed (20). Due to the phrasing of the questions (and the high correlation between the measures for the 2 sides) the mean values of the right and left sides were used.

All the subjects kept a worktask diary on the day the recordings were made and also on 9 additional days. Before the subjects started filling out the diaries, they were interviewed about their work by an experienced physiotherapist, and the relevant worktasks to be used as entries in the diary were defined by the physiotherapist in collaboration with the subject. Each subject was then asked to note the start and stop of these tasks, and also lunch and breaks and pauses.

For each subject, on the basis of the measurements during the specified worktasks (ie, the task exposure) and the 2-week diary information on the duration of each task, time-weighted values of postures and movements were calculated $(7,27)$. These values - the timeweighted job exposure (16) — were used for evaluating the questionnaire-assessed data. Lunch, coffeebreaks, and other pauses (eg, for smoking) were not included.

Measured workday exposure (ie, the measured exposure during the day of the recordings), after the 
exclusion of lunch, breaks and pauses, was also derived from the measurements.

Due to practical and technical limitations, inclinometer measurements were not performed for 4 subjects. Moreover, 3 inclinometer measurements for the head, 5 inclinometer measurements for the upper back, and 2 goniometer measurements were lost due to technical problems. Regarding the questions about mechanical exposure, the subjects missed an average of 0.7 (range $0-2$ ) of the 7 questions.

\section{Statistics}

Kappa statistics, supplemented by the percentage of agreement, were used as a measure of agreement between the response category and the categorized timeweighted job exposure, both within each occupational group and in the whole material. For each calculation of kappa ( $\kappa)$, the material was trichotomized according to the time-weighted job exposure. The sizes of these groups were chosen to be equal to the number in each response category, in a way that would give complete agreement $(\kappa=1)$, if the responses were rank-ordered according to the time-weighted job exposure. The level of significance was chosen as $\mathrm{P}<0.05$.

\section{Results}

\section{Time weighted job exposure}

The time-weighted job exposure covered the major part of the work that was recorded in the 2-week diary. The number of work tasks occurring in the diaries averaged
6.8 (range 2-13) and the average number recorded during the day the measurements were performed was 3.5 (range 1-7). The fraction of time for the worktasks in the 2-week diary, which was covered by measurements, averaged $78 \%$ (range 12-100\%).

The differences between the measured workday exposure and the time-weighted job exposure were small. Regarding movements, the average relative difference, for the 90th percentiles, was 1 (SD 11)\% and the coefficient of determination $\left(r^{2}\right)$ ranged from 0.96 to 0.97 (figure 1a). For the postures, the average difference was $<0.5$ (SD 2) degrees for the 10th and 90th percentiles, and the coefficient of determination ranged from 0.95 to 0.98 (figure 1b). Accordingly, the results were similar, and the conclusions the same, whether the timeweighted job exposure or the measured workday exposure was used for the evaluation. Moreover, the results were not sensitive to the use of the 1st and 99th percentiles as alternatives to the 10th and 90th percentiles, respectively (not in table).

There was a considerable difference between the office workers and the cleaners in their time-weighted job exposure and their questionnaire responses (figures 1 and 2). There were also large variations within the 2 groups. Regarding movements, the time-weighted job exposure almost completely separated the 2 groups, while there was an overlap for postures.

\section{Agreement between questionnaire-assessed exposure and time weighted job exposure}

Regarding movements, the results were not sensitive to the use of angular acceleration, velocity $<1$ degree/second or repetitiveness, as alternatives to angular velocity for the wrists (table 3). We found no agreement between
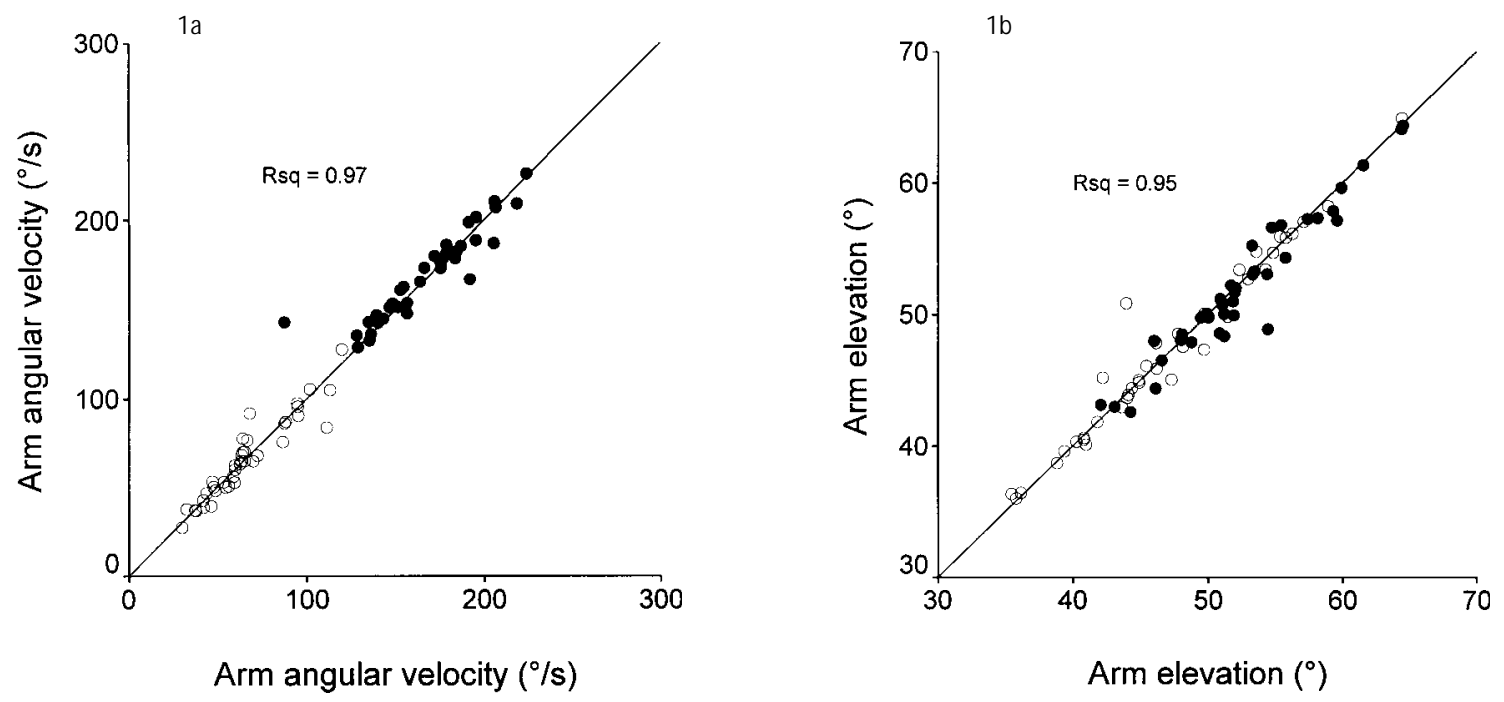

Figure 1. Relation between measured whole-day exposure (y-axis) and time-weighted job exposure (x-axis) for arm movements (a) and arm elevation (b). The line of identity and the coefficient of determination (Rsq) are also shown, and the symbols denote office workers (open circles), cleaners (closed circles), and degrees $\left(^{\circ}\right)$ 

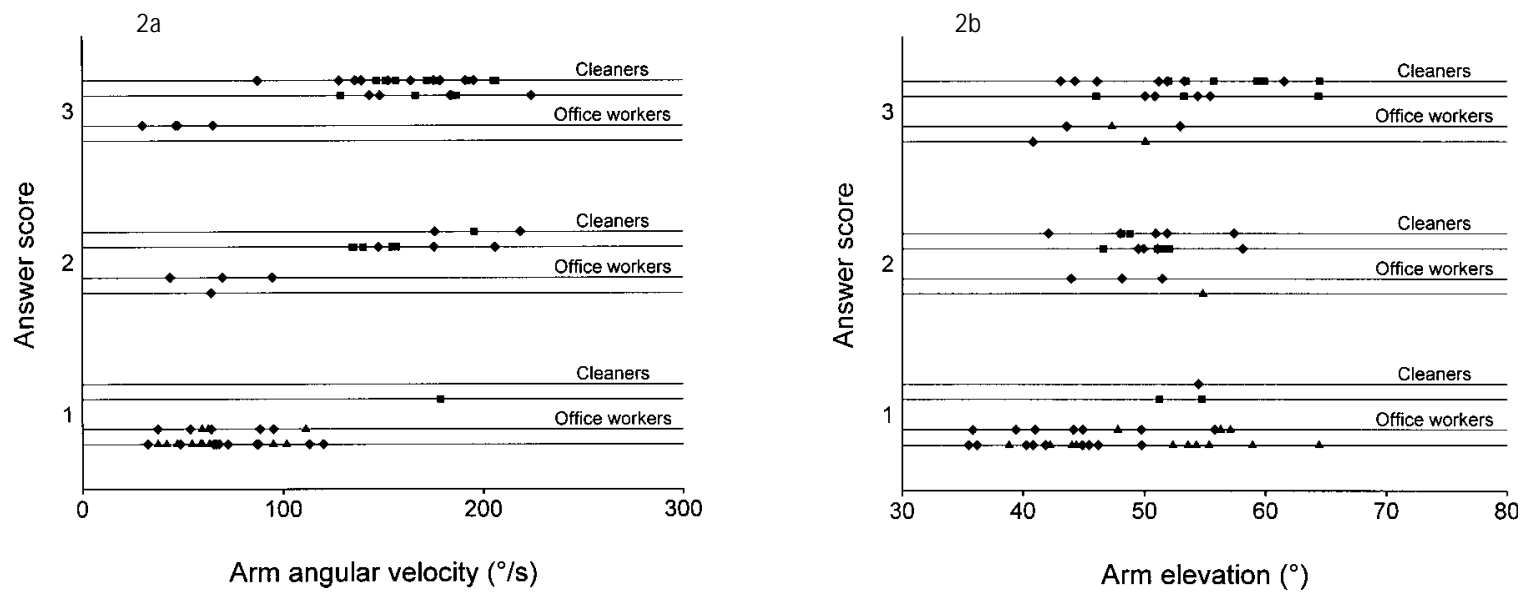

Figure 2. Relation between questionnaire-assessed exposure regarding repetitive arm movements (a) and elevated arms (b) and time-weighted job exposure, occupation, neck-shoulder complaints, gender and age for 78 subjects. The scores 1,2 , and 3 correspond to the answers "very little or not at all", "somewhat" and "much", respectively. Within each occupational group, the upper of the2 lines represents subjects with neck-shoulder complaints and the lower represents subjects without complaints. The symbols denotefemales $\geq 45$ years (diamonds), males $\geq 45$ years (triangles), females $<45$ years (squares), and degrees $(\stackrel{\circ}{)}$.

Table 3. Agreement between the questionnaire-assessed movements and time-weighted job exposure in the whole material and among office workers and cleaners separately. (Very little $=$ very little or not at all)

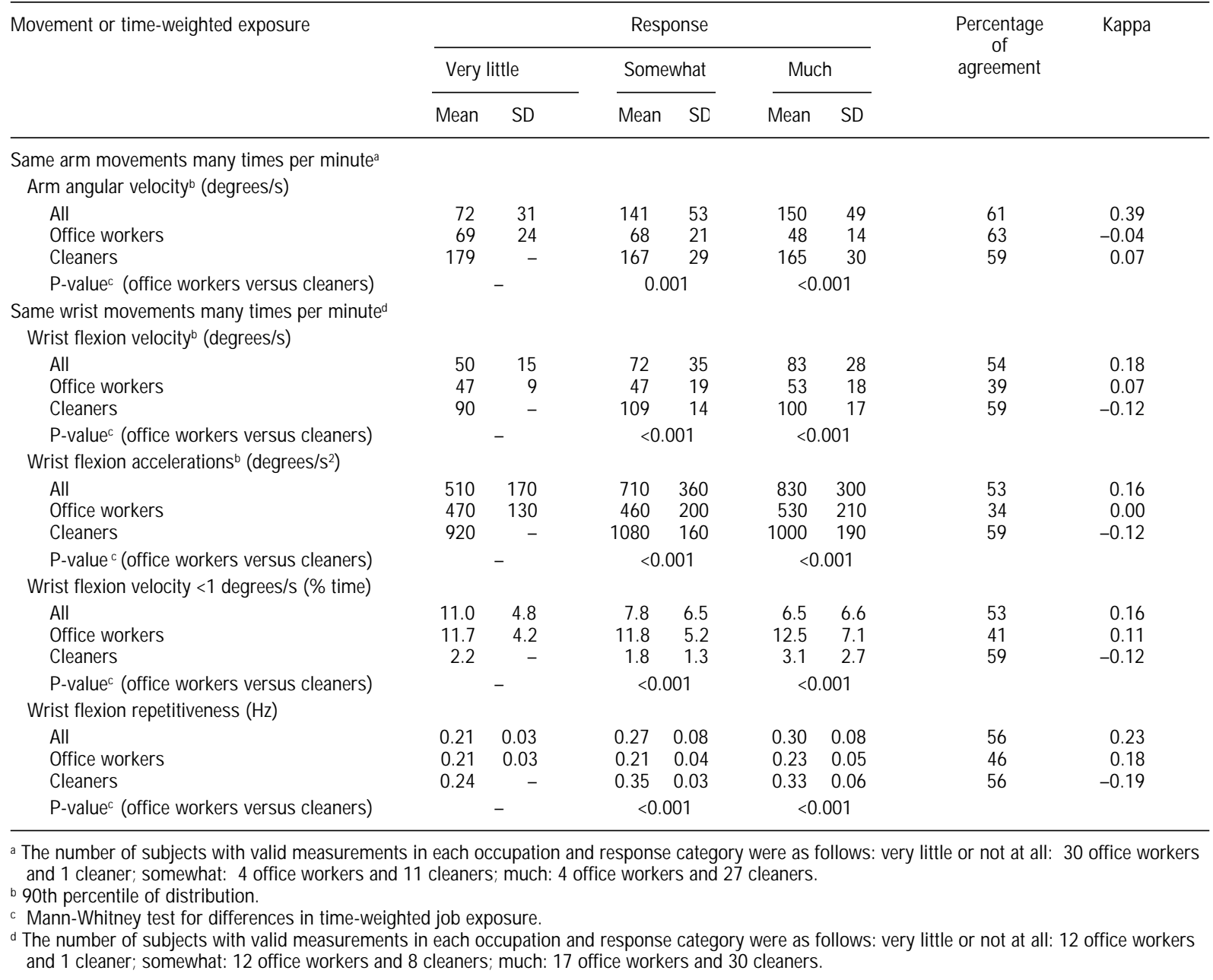


Table 4. Agreement between questionnaire-assessed postures and time-weighted job exposure in the whole material and among the office workers and cleaners separately. (Very little = very little or not at all)

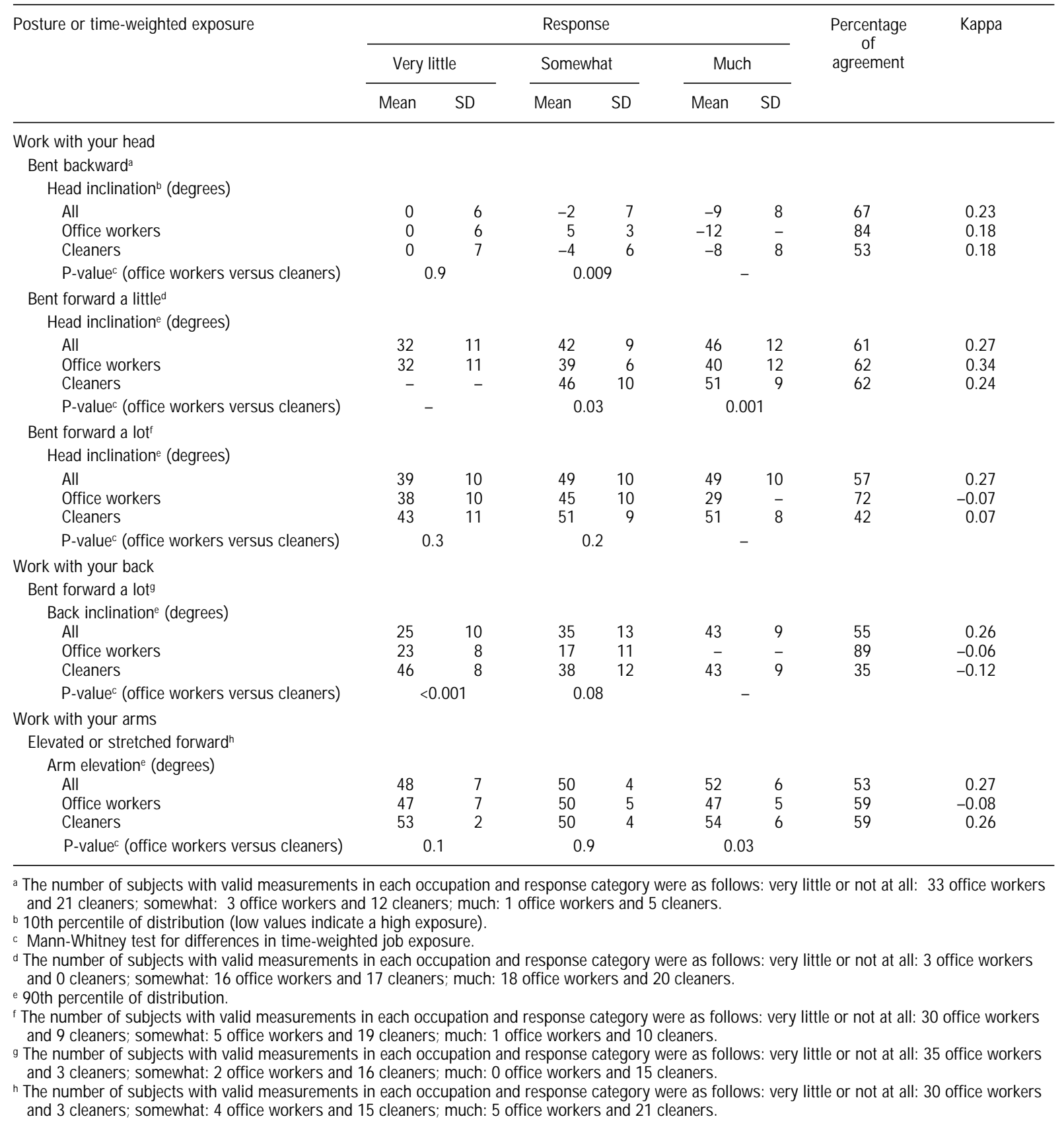

the responses and time-weighted job exposure within the occupational groups, on the average, for velocity, $\kappa=-0.01$ (table 3 , figure $2 \mathrm{a}$ ). Although the agreement, as expected, was higher for the groups combined, it was still low, on the average $\kappa=0.29$.

Regarding postures, there was almost no agreement within the occupational groups, on the average $\kappa=0.09$ (table 4, figure 2b). For the whole material, the agreement was higher, on the average $\kappa=0.26$.

When we restricted the analysis, for the whole material, to subjects without neck-shoulder complaints, we obtained, in general, higher kappa values (averaging $\kappa=0.37$ for movements and $\kappa=0.34$ for postures) (not in table).

\section{Effect of occupation}

Belonging to an occupational group affected the relation between the time-weighted job exposure and the questionnaire responses. For the same response, the time-weighted job exposure was, in general, higher for the cleaners than for the office workers (tables 3 and 4). These differences were considerable. Regarding 
Table 5. Associations between the questionnaire-assessed exposure and neck-shoulder complaints and time-weighted job exposure for the 90th percentiles (10th for "head bent backward") of the corresponding distributions. For the head, back, arms and wrists, 7, 9, 4 and 2 measurements, respectively, were missing. (Very little = very little or not at all)

\begin{tabular}{|c|c|c|c|c|c|c|c|c|c|c|c|c|c|c|c|c|c|}
\hline \multirow[t]{4}{*}{ Exposure } & \multicolumn{8}{|c|}{ Office workers } & \multicolumn{8}{|c|}{ Ceaners } & \multirow{4}{*}{$\frac{\text { All }}{\text { Diff }_{\text {exp }}}$} \\
\hline & \multicolumn{6}{|c|}{ Complaints } & $P_{\text {ans }}{ }^{a}$ & Diff $_{\exp }{ }^{b}$ & \multicolumn{6}{|c|}{ Complaints } & \multirow[t]{3}{*}{$\mathrm{P}_{\text {ans }}{ }^{\mathrm{a}}$} & \multirow[t]{3}{*}{ Diff $_{\text {exp }}{ }^{b}$} & \\
\hline & \multicolumn{3}{|c|}{ No $(\mathrm{N}=24)$} & \multicolumn{3}{|c|}{ Yes $(\mathrm{N}=17)$} & & & \multicolumn{3}{|c|}{ No $(\mathrm{N}=17)$} & \multicolumn{3}{|c|}{ Yes $(\mathrm{N}=24)$} & & & \\
\hline & $\begin{array}{l}\text { Very } \\
\text { little }\end{array}$ & $\begin{array}{l}\text { Some- } \\
\text { what }\end{array}$ & Much & $\begin{array}{l}\text { Very S } \\
\text { little }\end{array}$ & $\begin{array}{l}\text { ome- } \\
\text { what }\end{array}$ & Much & & & $\begin{array}{l}\text { Very } \\
\text { little }\end{array}$ & $\begin{array}{l}\text { Some- } \\
\text { what }\end{array}$ & - Much & $\begin{array}{l}\text { Very } \\
\text { little }\end{array}$ & $\begin{array}{l}\text { Some } \\
\text { what }\end{array}$ & Much & & & \\
\hline \multicolumn{18}{|l|}{ Postures } \\
\hline \multicolumn{18}{|l|}{ Head } \\
\hline Bent backward & 21 & 0 & 0 & 12 & 3 & 1 & 0.03 & 1 & 11 & 4 & 1 & 10 & 8 & 4 & 0.2 & -3 & -10 \\
\hline Bent forward a little & 2 & 11 & 8 & 1 & 5 & 10 & 0.2 & -2 & 0 & 9 & 7 & 0 & 8 & 13 & 0.3 & -4 & 13 \\
\hline Bent forward a lot & 17 & 2 & 1 & 13 & 3 & 0 & 1.0 & -2 & 6 & 6 & 4 & 3 & 13 & 6 & 0.4 & -4 & 14 \\
\hline \multicolumn{18}{|l|}{ Back } \\
\hline Bent forward a lot & 20 & 1 & 0 & 15 & 1 & 0 & 1.0 & 2 & 2 & 8 & 4 & 1 & 8 & 11 & 0.1 & 1 & 20 \\
\hline \multicolumn{18}{|l|}{ Arms } \\
\hline $\begin{array}{l}\text { Bevated or stretched } \\
\text { forward }\end{array}$ & 20 & 1 & 2 & 10 & 3 & 3 & 0.1 & 0 & 2 & 8 & 7 & 1 & 7 & 14 & 0.2 & 0 & 10 \\
\hline \multicolumn{18}{|l|}{ Movements } \\
\hline Arms many times/minute & 22 & 1 & 0 & 8 & 3 & 4 & 0.002 & -3 & 1 & 8 & 8 & 0 & 3 & 19 & 0.01 & 3 & 106 \\
\hline Wrists many times/minute & 7 & 9 & 8 & 5 & 3 & 9 & 0.4 & -2 & 1 & 6 & 10 & 0 & 2 & 20 & 0.02 & 7 & 55 \\
\hline
\end{tabular}

a P-value for difference in responses between the subjects with and those without neck-shoulder complaints (Jonckheere-Terpstra test for trend).

${ }^{b}$ Difference [in the number of degrees (postures) or number of degrees per second (movements)] in the mean time-weighted job exposure between the subjects with and those without neck-shoulder complaints.

${ }^{\circ}$ Difference [in the number of degrees (postures) or number of degrees per second (movements)] between the 75th and 25th percentile of the time weighted job exposure.

movements, the time-weighted job exposure was twice as high for all the response categories and statistically significant for the cleaners (as compared with the office workers). Regarding postures, the differences were statistically significant for 5 of the 11 response categories for which tests could be performed. For example, the cleaners who answered "much" regarding work with their heads bent forward a little averaged a considerably higher $(11=51-40$ degrees $)$ (table 4$)$ head inclination than the office workers who gave the same response.

\section{Differential misclassification}

Within each occupational group, the differences in the time-weighted job exposure between subjects with and without neck-shoulder complaints were small and statistically nonsignificant. For example, the differences between the persons with and those without complaints, regarding the 90th percentile of head inclination, averaged 2 and 4 degrees for the office workers and cleaners, respectively, and thus was small, as compared with the variation in the time-weighted job exposure (table 5). Persons with neck-shoulder complaints gave exposure regarding movements a higher rating, and also had a general tendency to rate their exposure regarding postures higher, than did those without complaints, although the differences in the time-weighted job exposure could be disregarded (table 5, figure 2).

Among the office workers, the men had a significantly higher (90th percentile of 7 degrees) time-weight- ed job exposure to arm elevation than did the women, although they did not rate their exposure higher (not in table). Moreover, although the differences in the measured exposure could be disregarded, the self-assessed exposure was lower for the men than for the women for the questions regarding "head bent forward a little" $(\mathrm{P}=0.02$, Jonckheere-Terpstra test for trend) and repetitive arm movements $(\mathrm{P}<0.01)$. For wrist movements the men rated their exposure lower than the women; however, since also their measured exposure was lower, differential misclassification due to gender could not be evaluated for this item.

Regarding age, cleaners $\geq 45$ years of age worked with the head bent more forward (7 degrees) and less backward (5 degrees) than did the cleaners who were $<45$ years of age (not in table). Since they also rated their exposure accordingly, misclassification due to age could not be studied for the questions regarding head postures. For the remaining questions, no significant differential misclassification due to age was found for the cleaners for either movements or postures.

\section{Discussion}

The agreement between the questionnaire responses and the technically measured movements and postures was low. Among the cleaners and office workers who gave the same response, the former had a higher time-weight- 
ed job exposure. For the same measured exposure, the subjects with neck-shoulder complaints rated, in general, their subjective exposure higher than did those without.

\section{Aspects of selection, measurement bias and statistics}

In spite of the relatively large study base, we obtained fewer male office workers with complaints and cleaners without complaints than was our aim. This result is reflected in the low and high prevalence, respectively, of work-related musculoskeletal disorders in these groups. Since the participation rate was high, the only consequence was a loss of statistical power.

It is possible that people change their way of working when measurements are performed. However, the equipment had a low weight, and we did not observe any obvious influence on work performance.

The main error of the goniometer is crosstalk between flexion and deviation, which increases with increasing rotation of the forearm $(20,26)$. In contrast to Hansson et al (20), Buchholtz \& Wellman (26) also found a zero drift error due to forearm rotation; this difference is probably due to the fact that Buchholtz \& Wellman referred their equations to the neutral position of the wrist, which implies an individual-related flexion and deviation of the goniometer. Although crosstalk, in pronounced flexion-extension or deviation of the wrist combined with simultaneous pronation-supination of the wrist, introduces considerable momentary errors, the widening of the flexion and deviation angle distributions may still be moderate. Furthermore, the presence of angular errors does not necessarily imply that the errors of the calculated movement measures are of a corresponding size. Moreover, we used the flexion measures, rather than the deviation ones, since, due to the lower functional range of motion for deviation than for flexion, the relative error is less for flexion than for deviation (20). Simultaneous measurement of supination-pronation would enable correction - and quantitative estimates - of the errors in the flexion and deviation recordings $(20,26)$.

The calculation of movements (eg, angular velocity and acceleration) from the 1 st and 2 nd time derivatives, respectively, may introduce large errors if the sampling frequency, filters, and algorithms are not adequate (28). In our study, the values for these parameters were chosen according to the frequency content of the wrist angle recordings to be optimal for manual work (20).

Movements of the skin on which the transducers are attached, relative to the skeleton, which is the ultimate reference of segment orientation and joint angles, introduce errors. For the inclinometers on the head and upper back, these movements were assumed to be small, and for the upper arms, the use of plastic plates, positioned below the deltoid muscle, presumably reduced this type of error. Regarding the goniometer, based on a comparison of our wrist mobility data (20) with later reported ones (29), the error seems reasonable and can be estimated to be 5 degrees in extreme positions.

Since the inclinometers and goniometers have a high precision and the reference positions were recorded in standardized ways, the variance introduced by the measurements was small, especially so for the movement measures, which are insensitive to the recording of the reference position, as well as to any drift of the transducers. Day-to-day variations in an individual's performance of worktasks would also contribute to the variation in time-weighted job exposure. Both these factors would decrease the kappa values; however the effect was probably limited.

The question regarding "arms elevated or stretched forward" was ambiguous for flexed positions of the trunk, since a reference was not given. However, using the torso as the reference - rather than the line of gravity - would not a priori provide better agreement between the questionnaire responses and the measurements.

For repetitive arm movements, angular velocity may not exactly correspond to repetitiveness, and, if so, the difference may have contributed to the low kappa values. However, for wrist movements, which included measures of angular velocity, angular acceleration, the fraction of time that the hands were held still, and repetitiveness, all the measures gave similar kappa values. Hence, at least for wrist movements, the low agreement is fundamental and not due to the choice of movement measure.

The difference between the time-weighted job exposure and the measured workday exposure was small. However, the situation may have not been the same for occupations with a large day-to-day variation of tasks that vary greatly in exposure. For our material, the gain of data collected from a worktask diary does not seem worth the effort. Indeed, for 6 subjects, we performed whole-day measurements that could not be included in our present study, due to the lack of an acceptable diary. Still, since we had the diary information for most of the subjects, we decided to use the time-weighted values.

Kappa statistics is a relevant measure of agreement, since the kappa value, in contrast to percentage of agreement, is adjusted for agreement by chance. The relation between the kappa value and the percentage of agreement provides additional information (eg, regarding the distributions of the observations). For example, if the responses are concentrated at the lowest score (and hence due to the procedure of trichotomization, also the categorized measures), the kappa value may be low, although the percentage of agreement may approach 100. This effect was seen, for example, for the question 
regarding "head bent backward" (percentage of agreement $=84$ and $\kappa=0.18)($ table 4$)$. The trichotomization used in the kappa analysis did not require an a priori assumption about the cutoff values and was chosen so that $\kappa=1$ would be obtained when the responses were rank ordered according to the time-weighted job exposure. The present kappa values were far lower, partially due to differential misclassification.

\section{Effect of occupation}

For the same response, the cleaners had a higher measured mechanical exposure than the office workers. This difference was not due to the higher prevalence of workrelated musculoskeletal disorders among the cleaners, as the material was stratified in this respect. Instead, it was probably caused by varying frames of reference, which may be influenced by, for example, the prevailing opinion about the risk factors for work-related musculoskeletal disorders.

As a consequence, the use of questionnaire-assessed exposure data in epidemiologic studies of populations with a large variation of occupations and workloads would probably result in a spuriously low range of subjective exposure, with too few subjects in both the low and the high strata. In turn, this situation will result in too flat an exposure-response curve for work-related musculoskeletal disorders, with an overestimate of the risk at low exposure and an underestimate at high exposure. Our findings show that such a possibility is particularly important for movements, but less so for positions.

In another Malmö shoulder-neck study of questionnaire-assessed mechanical exposure, there was a clear exposure-response relation (Balogh et al, unpublished manuscript). Considering the preceding misclassification of exposure, the true effect should be even stronger.

For our material, the questionnaire responses were blunt in relation to the measured exposure to movements. The large difference, and almost complete separation, between the 2 occupations was diminished. This is of special importance since recent epidemiologic studies using technical measures have shown that movement, rather than posture, is a risk factor for work-related musculoskeletal disorders of the wrist (30-33).

Moreover, using questionnaires for stratifying subjects into groups that are supposedly equally exposed to mechanical load as a 1st step for studying other potential risk factors does not seem appropriate.

\section{Differential misclassification due to musculoskeletal complaints}

Within each occupational group, subjects with neckshoulder complaints had time-weighted job exposures almost identical to those without. The verification by direct measurements enabled us to evaluate the differential misclassification. Indeed, subjects with complaints rated their exposure considerably higher than did healthy ones. It can be argued that subjects who experience pain change their way of working and thus reduce their exposure, as we earlier reported for dentists (22). Hence, self-reported exposure may be more relevant with respect to risk than technically measured exposure is. However, our questions concerned the current workload. In addition, dentists have a possibility to reduce their load, while reducing load was probably not an option for the subjects of our study. In accordance with this assumption, industrial workers with complaints did not have a lower exposure than others in another study (24). Instead, the pain is the probable cause of the higher exposure rating. Misclassification has often been suspected but seldom studied, and, if so, often with a poor design. In a study regarding subjective arm position (12), it was concluded that "substantial differential misclassification of exposure was not present", in spite of the fact that the data indicated such. Other data also support misclassification (5-7).

Differential misclassification is a problem in the interpretation of any cross-sectional association between exposure and work-related musculoskeletal disorders. For example, such an association was used to verify the validity of an exposure questionnaire (10) when misclassification bias is as likely an explanation.

Discomfort focuses the attention on work postures and movements. The perception of mechanical load is complex and involves both the peripheral (eg, mechanoreceptors, proprioceptors and nociceptors) and central nervous systems. Indeed, it can be hypothesized that the perception of mechanical load may be an early step in developing work-related musculoskeletal disorders.

The effect of dependent misclassification due to complaints would be eliminated by prospective studies of initially healthy subjects. Such studies are often suggested, but scarcely used. However, if perceived high workload is a precursor to disorders, even prospective questionnaire-based studies may overestimate the effect of the exposure.

\section{Use of direct technical exposure measures}

In our material, questionnaires supplied less information on the actual movements than did job title. However, the exposure in specific jobs is seldom known in quantitative terms. This problem can be overcome by establishing a job-exposure matrix (34) by combining technical exposure measurements (23). Within specific occupations, this concept can be specified using a task-exposure matrix. However, due to the large interindividual variation when the same task is performed (24), information in the matrix needs ranges. Thus direct measurement may have to be considered when 
valid estimates of mechanical exposure are required at the individual level.

\section{Acknowledgments}

This study was supported by the Swedish Medical Research Council, the Swedish Council for Work Life Research, the Swedish National Institute for Working Life (cooperative for the optimization of industrial production systems regarding productivity and ergonomics), the Swedish Council for Planning and Coordination of Research, and the Medical Faculty of Lund University.

Ms Lothy Granqvist provided skillful technical assistance.

\section{References}

1. Westgaard RH, Winkel J. Ergonomic intervention research for improved musculoskeletal health: a critical review. Int J Ind Ergon 1997;20:463—500.

2. Buckle P. Upper limb disorders and work: the importance of physical and psychosocial factors. J Psychosom Res 1997;43:17-25.

3. Ektor-Andersen J, Isacsson S-O, Lindgren A, Ørbæk P, The Malmö Shoulder-Neck Study group. The experience of pain from the shoulder-neck area related to the total body pain, self-experienced health and mental distress. Pain 1999;82:289-95.

4. Burdorf A, van der Beek AJ. In musculoskeletal epidemiology are we asking the unanswerable in questionnaires on physical load? Scand J Work Environ Health 1999;25: $81-3$.

5. Wiktorin C, Karlqvist L, Winkel J, Stockholm MUSIC I study group. Validity of self-reported exposures to work postures and manual materials handling. Scand J Work Environ Health 1993;19:208-14.

6. Van der Beek AJ, Braam IT, Douwes M, Bongers PM, Frings Dresen $\mathrm{MH}$, Verbeek JH, et al. Validity of a diary estimating exposure to tasks, activities, and postures of the trunk. Int Arch Occup Environ Health 1994;66:173 - 8.

7. Viikari-Juntura E, Rauas S, Martikainen R, Kuosma E, Riihimäki H, Takala E-P, et al. Validity of self-reported physical work load in epidemiologic studies on musculoskeletal disorders. Scand J Work Environ Health 1996;22:251—9.

8. Toomingas A, Alfredsson L, Kilbom A. Possible bias from rating behavior when subjects rate both exposure and outcome. Scand J Work Environ Health 1997;23:370-7.

9. Pope DP, Silman AJ, Cherry NM, Pritchard C, Macfarlane GJ. Validity of a self-completed questionnaire measuring the physical demands of work. Scand J Work Environ Health 1998;24:376-85.

10. Hollmann S, Klimmer F, Schmidt K-H, Kylian H. Validation of a questionnaire for assessing physical work load. Scand J Work Environ Health 1999;25:105-14.

11. Torgén M, Winkel J, Alfredsson L, Kilbom Å, Stockholm MUSIC 1 Study Group. Evaluation of questionnaire-based information on previous physical work loads. Scand J Work Environ Health 1999;25:246-54.

12. Wiktorin C, Vingård E, Mortimer M, Pernold G, WigaeusHjelm E, Kilbom $\AA$, et al. Interview versus questionnaire for assessing physical loads in the population-based MUSICNorrtälje Study. Am J Ind Med 1999;35:441—55.

13. Petersson NF, Mathiassen SE, Björing G, Winkel J. The accuracy of self-rating of exposure to repetitive work. Int $\mathbf{J}$ Ind Ergon 2000;25:239—46.

14. Frese M, Zapf D. Methodological issues in the study of work stress: objective vs. subjective measurements of work stress and the question of longitudinal studies. In: Cooper CL, Payne R, editors. Causes, coping, and consequences of stress at work. Chichester, England: Wiley, 1988:375-411.

15. Kasl SV. Measuring job stressors and studying the health impact of the work environment: an epidemiologic commentary. J Occup Health Psychol 1998;3:390 - 401.

16. Winkel J, Mathiassen SE. Assessment of physical work load in epidemiologic studies: concepts, issues and operational considerations. Ergonomics 1994;37:979—88.

17. Van der Beek AJ, Frings Dresen MH. Assessment of mechanical exposure in ergonomic epidemiology. Occup Environ Med 1998;55:291-9.

18. Hansson G- $\AA$, Björn F, Carlsson P. A new triaxial accelerometer and its application as an advanced inclinometer. In: 9th International Congress of ISEK; 1992 June 28-July 2; Florence, Italy; Abstracts. 1992:207.

19. Asterland P, Hansson G- $\AA$, Kellerman M. New data logger system for work load measurements - based on PCMCIA memory cards. In: 25th International Congress on Occupational Health; 1996 Sept 15-20; Stockholm, Sweden; Abstracts:Part I, 1996:273.

20. Hansson G-Å, Balogh I, Ohlsson K, Rylander L, Skerfving $\mathrm{S}$. Goniometer measurements and computer analysis of wrist angles and movements applied to occupational repetitive work. J Electromyogr Kinesiol 1996;6:23-35.

21. Kuorinka I, Jonsson B, Kilbom Å, Vinterberg H, BieringSørensen F, Andersson G, et al. Standardized Nordic questionnaire for the analysis of musculoskeletal symptoms. Appl Ergon 1987;18:233-7.

22. Åkesson I, Hansson G-Å, Balogh I, Moritz U, Skerfving S. Quantifying work load in neck, shoulders and wrists in female dentists. Int Arch Occup Environ Health 1997;69: $461-74$.

23. Hansson G-Å, Mikkelsen S. Kinematic evaluation of occupational work. Adv Occup Med Rehabil 1997;3:57-69.

24. Balogh I, Hansson G-Å, Ohlsson K, Strömberg U, Skerfving S. Interindividual variation of physical load in a work task. Scand J Work Environ Health 1999;25:57-66.

25. Stål M, Hansson G-Å, Moritz U. Wrist positions and movements as possible risk factors during machine milking. Appl Ergon 1999;30:527-33.

26. Buchholz B, Wellman, H. Practical operation of a biaxial goniometer at the wrist joint. Hum Factors 1997;39: 119-29.

27. Karlqvist L, Winkel J, Wiktorin C. Direct measurements and systematic observations of physical workload among medical secretaries, furniture removers and male and female reference populations. Appl Ergon 1994;25:319-26.

28. Giakas G, Baltzopoulos V. Optimal digital filtering requires a different cut-off frequency strategy for the determination of the higher derivatives. J Biomech 1997;30:851-5.

29. Marshall MM, Mozrall JR, Shealy JE. The effects of complex wrist and forearm postures on wrist range of motion. 
Hum Factors 1999;41:205-13.

30. Marras WS, Schoenmarklin RW. Wrist motions in industry. Ergonomics 1993;36:341-51.

31. Malchaire JB, Cock NA, Robert AR. Prevalence of musculoskeletal disorders at the wrist as a function of angles, forces, repetitiveness and movement velocities. Scand J Work Environ Health 1996;22:176-81.

32. Malchaire JB, Cock NA, Piette A, Dutra Leao R, Lara M, Amaral F. Relationship between work constraints and the development of musculoskeletal disorders of the wrist: A prospective study. Int J Ind Ergon 1997;19:471—82.

33. Hansson G-Å, Balogh I, Ohlsson K, Pålsson B, Rylander L, Skerfving S. Impact of physical exposure on neck and upper limb disorders in female workers. Appl Ergon 2000;31: 301-10.

34. Kauppinen T, Toikkanen J, Pukkala E. From cross-tabulations to multipurpose exposure information systems: a new job-exposure matrix. Am J Ind Med 1998;33:409-17.

Received for publication: 2 February 2000 